\title{
Synthesis, Characterization and Mechanical Behaviour of $\mathrm{Al}_{2} \mathrm{O}_{3}$, $\mathrm{TiO}_{2}$, and Cu Reinforced Al 7068 Nanocomposites
}

\author{
V. Sathiyarasu', D. Jeyasimman ${ }^{2, *}$ and L. Chandra Sekaran ${ }^{1}$ \\ ${ }^{1}$ Department of Mechanical Engineering, Mookambigai College of Engineering, Pudukkottai- 622502, Tamil \\ Nadu, India and ${ }^{2}$ Department of Mechanical Engineering, Periyar Maniammai Institute of Science \& \\ Technology, Thanjavur -613403, Tamil Nadu, India
}

\begin{abstract}
This present research work aims at fabrication of AA7068 metal matrix composite reinforced w ith a different w eight percentage of $\mathrm{Al}_{2} \mathrm{O}_{3}, \mathrm{TiO}_{2}$ and $\mathrm{Cu}(0 \mathrm{wt} . \%, 2 \mathrm{wt} \%$, and $4 \mathrm{wt} . \%)$ nanopow ders through mechanical alloying of 30 hrs which is produced using pow der metallurgy route. The consolidation pressure of $500 \mathrm{MPa}$ was applied for compaction of the composite and sintered at a temperature of $600^{\circ} \mathrm{C}$ for tw o hrs in the presence of argon gas flow. An $\mathrm{XRD}$ result reveals that there are no intermetallic compounds formed in the milled pow der after $30 \mathrm{hr}$ of mechanical alloying. The reinforcement particles $w$ ere well embedded and uniformly distributed in matrix composites $w$ as confirmed by bright-field emission transmission electron microscopy (FETEM) image and selected area diffraction (SAD) ring pattern. From the DSC curve of AA 7068-2.0 w t. \% Al2O3, TiO2 and Cu nanocomposite pow ders after 30 hrs of mechanical alloying., the endothermic peak at $536.85^{\circ} \mathrm{C}$ corresponds to the melting of aluminium w hich was follow ed by a steady-state exothermic reaction at $579.51^{\circ} \mathrm{C}$ w as obtained. The green density and sintered density of prepared nanocomposites w ere calculated and compared. Brinell hardness test has been conducted and the maximum value of $192 \mathrm{BHN}$ w as obtained by adding a w eight percentage of $2 \mathrm{wt} \%$ of $\mathrm{Al}_{2} \mathrm{O}_{3}, \mathrm{TiO}_{2}$ and $\mathrm{Cu}$ particles.
\end{abstract}

Keywords: Nanocomposites, Mechanical Alloying, Characterization, Mechanical Behaviour.

\section{INTRODUCTION}

In recent years, hybrid reinforcements with metal matrix nanocomposites are a prime consideration to enhance mechanical properties [1]. Aluminium 7068 alloy is widely used in the automotive, aerospace Industries and ordinance applications due to good mechanical properties compared with other aluminium alloys. Titanium Dioxide $\left(\mathrm{TiO}_{2}\right)$ was used as reinforcement in epoxy-co-polyamide composite and got improvement in tensile strength and elastic modulus in the recent study [2]. The effect of copper $(\mathrm{Cu})$ addition in the aluminium matrix gave on the resultant hardness increment [3]. Alumina $\left(\mathrm{Al}_{2} \mathrm{O}_{3}\right)$ has excellent hardness, dielectric property, wear resistance and chemical inertness properties. The effect of various reinforcements in aluminum and magnesium metal matrix composites through various synthesis methods are analysed in Table 1.

Various authors have studied the effect of various reinforcements with aluminium metal matrix composites on mechanical properties and its microstructural analysis. However, there is limited work in the effect of hybrid reinforcement with 7068 aluminium alloy on mechanical properties and its microstructural analysis through mechanical alloying. Therefore, the main aim of the present research work is to study and investigate

*Address correspondence to this author at the Department of Mechanical Engineering, Periyar Maniammai Institute of Science \& Technology, Thanjavur -613403, Tamil Nadu, India; Tel: +91 9486020248; E-mail: jeyasimman76@gmail.com; jeyasimmand@pmu.edu

E-ISSN: $2410-4701 / 20$ the effect of $\mathrm{Al}_{2} \mathrm{O}_{3}, \mathrm{TiO}_{2}$ and $\mathrm{Cu}$ reinforced $\mathrm{Al} 7068$ alloy nanocomposites through mechanical alloying on its mechanical properties and its characterization analysis.

\section{EXPERIMENTAL PROCEDURE}

\subsection{Raw Materials}

Aluminium alloy 7068 was produced by blending of highly pure $(99.5 \%)$ elemental powders and 200-mesh size. The raw materials were purchased from High Purity Laboratory Company (HPLC), India. Table 2 shows the chemical composition to make aluminium alloy 7068 . Blending was done at high-energy ball mill at $250 \mathrm{rpm}$ for $2 \mathrm{hr}$.

\subsection{Processing of Nanocrystalline Powders}

Various weight percentages $(0 \%, 2 \%, 4 \%)$ of $\mathrm{Al}_{2} \mathrm{O}_{3}$, $\mathrm{TiO}_{2}$ and $\mathrm{Cu}$ reinforced $\mathrm{Al} 7068$ nanocomposite powders were prepared using a planetary ball mill. Balls of made up of tungsten carbide and $10 \mathrm{~mm}$ diameter each weighing $10 \mathrm{~g}$. Totally $300 \mathrm{~g}$ (30 balls) were sealed with $100 \mathrm{~g}$ of the $\mathrm{Al} 7068-\mathrm{Wt} \%, \mathrm{Al}_{2} \mathrm{O}_{3}, \mathrm{TiO}_{2}$ and $\mathrm{Cu}$ powder mixture. The speed of the mill is set to $250 \mathrm{rpm}$ and the processing time is set to 30 hours. However, 5 hours of milling is alternated with 20 min. of cooling to avoid a significant temperature rise.

\subsection{Compaction and Sintering}

The milled powders were consolidated into cylindrical pellets of $10 \mathrm{~mm}$ diameter $15 \mathrm{~mm}$ length using a

(c) 2020 Zeal Press 
Table 1: The Effect of Various Reinforcements in Aluminum and Magnesium Metal Matrix Composites

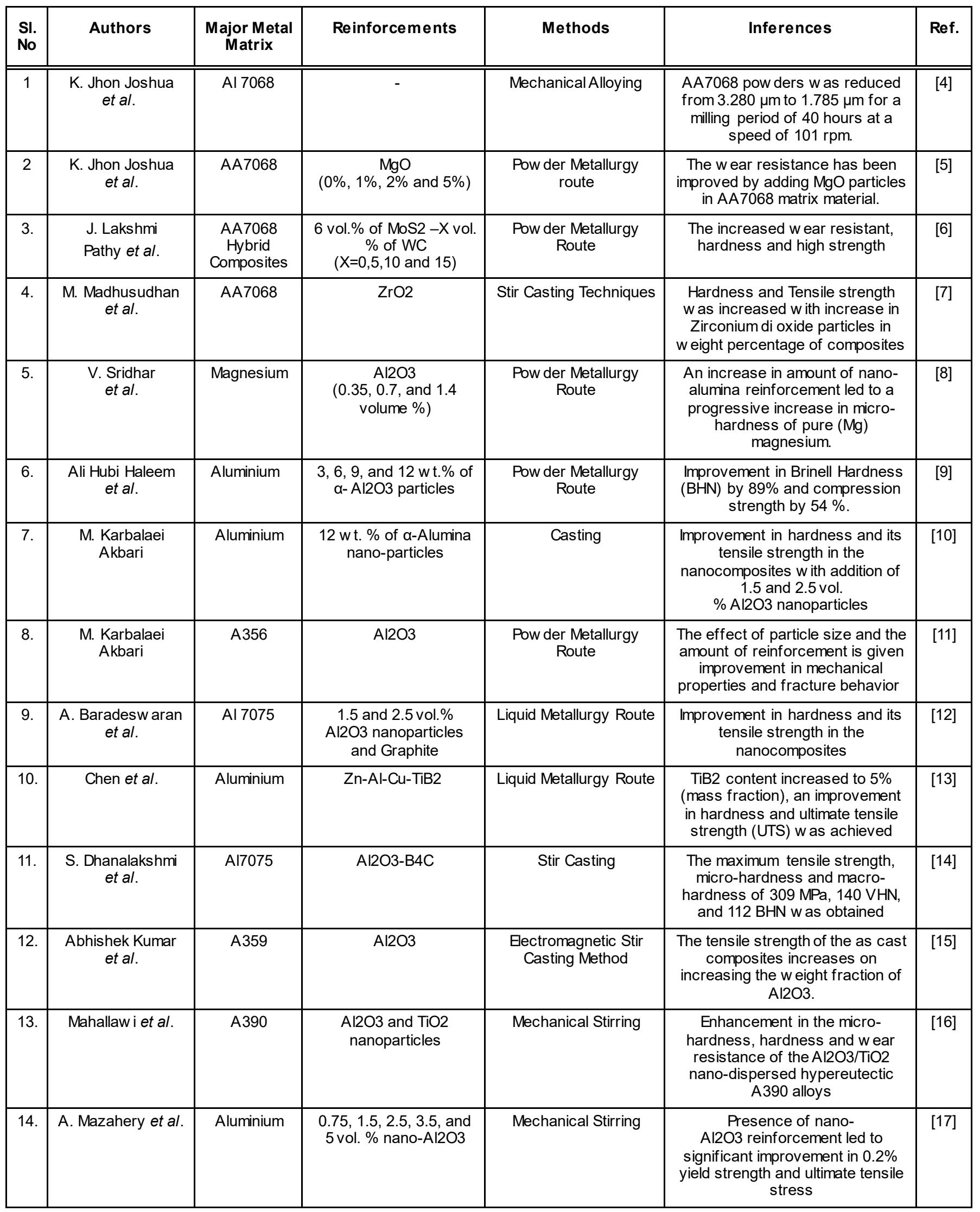


Table 1. contd....

\begin{tabular}{|c|c|c|c|c|c|c|}
\hline $\begin{array}{l}\text { SI. } \\
\text { No }\end{array}$ & Authors & $\begin{array}{l}\text { Major Metal } \\
\text { Matrix }\end{array}$ & Reinforcements & Methods & Inferences & Ref. \\
\hline 15. & Sahin et al. & Al 2014 & $\mathrm{Al} 2 \mathrm{O} 3$ & $\begin{array}{l}\text { Pow der Metallurgy } \\
\text { Route Method }\end{array}$ & $\begin{array}{l}\text { The w ear rate increased } w \text { ith } \\
\text { increasing the load and } \\
\text { decreased } w \text { ith increasing the } \\
\text { particle sizes for composites }\end{array}$ & [18] \\
\hline 16. & S.A. Sajjadi et al. & $\begin{array}{l}\text { A356 } \\
\text { Aluminium } \\
\text { Alloy }\end{array}$ & $\mathrm{Al} 2 \mathrm{O} 3$ & $\begin{array}{l}\text { Stir and Compo- } \\
\text { Casting Processes }\end{array}$ & $\begin{array}{l}\text { The improvement in yield } \\
\text { strength, ultimate tensile strength, } \\
\text { compression strength and } \\
\text { hardness w ere obtained }\end{array}$ & [19] \\
\hline 17. & S.A. Sajjadi et al. & $\begin{array}{l}\text { A356 } \\
\text { Aluminium } \\
\text { Alloy }\end{array}$ & $\begin{array}{l}\text { Micro and nano } \\
\text { level Al2O3 }\end{array}$ & $\begin{array}{l}\text { Stirring \& Compo- } \\
\text { Casting Method }\end{array}$ & $\begin{array}{l}\text { The amount of porosity in the } \\
\text { composites increased w ith } \\
\text { increasing w eight fraction and } \\
\text { speed of stirring and decreasing } \\
\text { particle size }\end{array}$ & {$[20]$} \\
\hline 19. & S. Tahamtan et al. & Al/A206 & $\begin{array}{l}\text { Nano and Micro } \\
\text { level } \mathrm{Al} 2 \mathrm{O} 3\end{array}$ & $\begin{array}{l}\text { Combining ball milling } \\
\text { and stir casting } \\
\text { technology }\end{array}$ & Improvement in tensile properties & {$[22]$} \\
\hline 20. & K. Umanath et al. & Al 6061 & $\mathrm{SiC} / \mathrm{Al} 2 \mathrm{O} 3$ & Liquid Metallurgy Route & $\begin{array}{l}\text { The w ear resistance of the } 15 \% \\
\text { hybrid composite was better than } \\
\text { that of the } 5 \% \text { hybrid composite }\end{array}$ & {$[23]$} \\
\hline 21. & Mohammed et al. & Aluminium & Graphene & $\begin{array}{l}\text { High energy ball milling } \\
\text { (HEBM) \& molecular } \\
\text { level mixing (MLM) } \\
\text { processes follow ed by } \\
\text { spark plasma sintering } \\
\text { (SPS) }\end{array}$ & $\begin{array}{l}\text { Improvement of } 79,49 \text { and } 44 \% \\
\text { of yield strength, ultimate } \\
\text { strength, and Vickers hardness, } \\
\text { respectively, for } 1 \mathrm{wt} \% \text { graphene } \\
\text { containing nanocomposite in } \\
\text { comparison to the unreinforced } \\
\text { Al-4Cu alloy }\end{array}$ & {$[24]$} \\
\hline 24. & $\begin{array}{l}\text { Meysam } \\
\text { Toozandehjani } \\
\text { et al. }\end{array}$ & $\mathrm{Al}$ & $\mathrm{Al} 2 \mathrm{O} 3$ & High Energy Ball Milling & $\begin{array}{l}\text { The increase in the milling time } \\
\text { resulted in the homogenous } \\
\text { dispersion of } 5 \mathrm{w} t \% \text { nanoparticles } \\
\text { and improvement in the density, } \\
\text { densification, micro-hardness } \\
(\mathrm{HV}) \text {, nano-hardness (HN), and } \\
\text { Young's modulus (E). }\end{array}$ & {$[27]$} \\
\hline 25. & Yilong Yang et al. & AA 2219 & $\mathrm{TiC}$ & Ultrasonic Solidification & $\begin{array}{c}\text { The average grain sizes of a-Al } \\
\text { matrix alloy reduced by } 61 \%\end{array}$ & [28] \\
\hline 26. & Julia Osten et al. & AA 7068 & $5 \% \mathrm{TiC}$ & $\begin{array}{l}\text { Mechanical Alloying } \\
\text { and Hot Pressing } \\
\text { routes }\end{array}$ & High Strength alloy developed & [29] \\
\hline 27. & Amin Azimi et al. & Al 7068 & $\mathrm{TiC}$ & Mechanical Alloying & $\begin{array}{c}\text { High compressive strength and } \\
\text { hardness of } 938 \mathrm{MPa} \text { and HV } 265 \\
\text { w ere achieved }\end{array}$ & {$[30]$} \\
\hline 28. & $\begin{array}{l}\text { R. Taherzadeh } \\
\text { Mousavian et. al }\end{array}$ & $\begin{array}{l}\text { A356 } \\
\text { aluminium } \\
\text { matrix }\end{array}$ & SiC nanoparticle & Mechanical Alloying & $\begin{array}{l}\text { Improvement in tensile strength } \\
\text { (UTS), yield strength (YS) and } \\
\text { strain }\end{array}$ & [31] \\
\hline
\end{tabular}




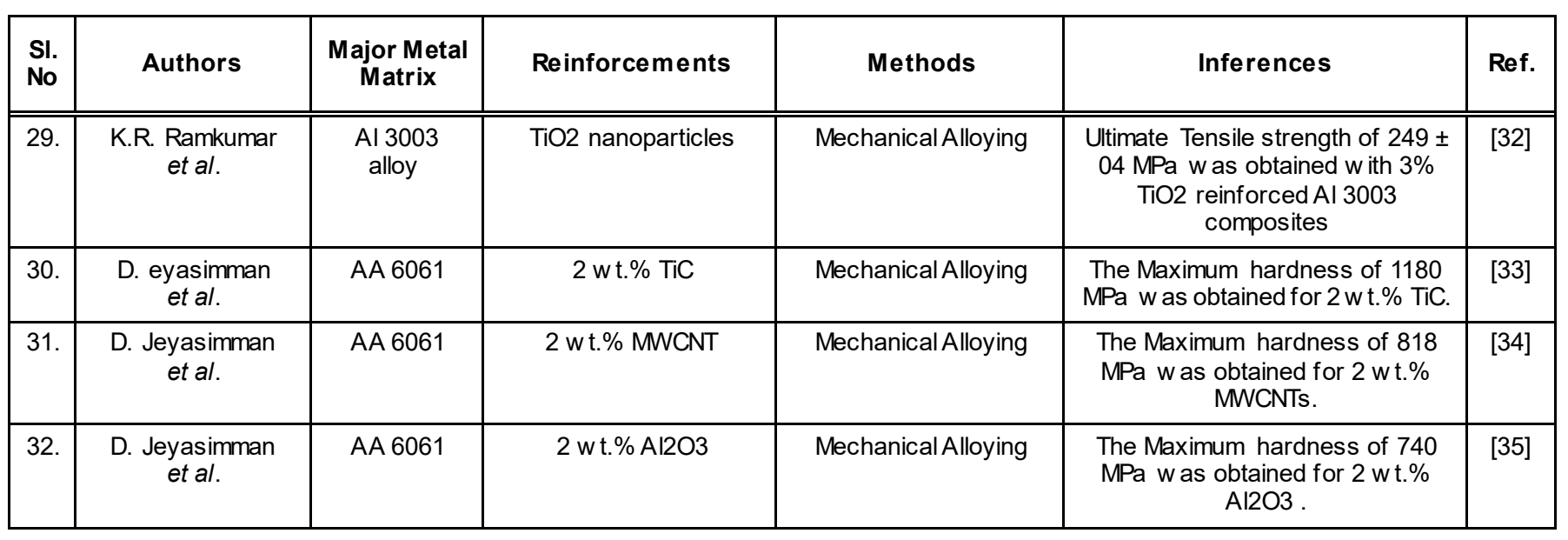

Table 2: Chemical Composition of Aluminium Alloy 7068

\begin{tabular}{|c|c|}
\hline Eement & Percentage \\
\hline \hline $\mathrm{Si}$ & 0.12 \\
\hline $\mathrm{Fe}$ & 0.15 \\
\hline $\mathrm{Cu}$ & 1.80 \\
\hline $\mathrm{Mn}$ & 0.10 \\
\hline $\mathrm{Mg}$ & 2.50 \\
\hline $\mathrm{Zn}$ & 8.00 \\
\hline $\mathrm{Ti}$ & 0.10 \\
\hline $\mathrm{Cr}$ & 0.05 \\
\hline $\mathrm{Zr}$ & 0.15 \\
\hline $\mathrm{Al}$ & Balance \\
\hline
\end{tabular}

hydraulic press with a capacity of 10 Tons at a compaction pressure of $500 \mathrm{MPa}$. The green pellets were sintered for 2 hours at $873 \mathrm{~K}$ under a reducing atmosphere and presence of the Argon gas flow. The theoretical densities of the samples were calculated using the rule of mixture. The density of sintered pellets was estimated precisely using the Archimedes principle. The estimated error in the density measurements was less than $1 \%$.

\subsection{Powder Morphology and Hardness Measure- ment}

Nanoparticles within the Al7068 matrix was investigated by scanning electron microscopy (SEM), X-ray diffraction (XRD), transmission electron microscopy (TEM) and differential scanning calorimetry (DSC). The crystallite size and lattice strain of the milled powder samples were investigated by X-ray diffraction analysis on a D/Max Ultima III; XRD machine (Rigaku Corporation, Japan). The samples were continuously exposed to $\mathrm{Cu} \mathrm{Ka}$ radiation $(\lambda=1.5406 \AA)$ at a scanning speed of $2^{\circ}$ per min. operating at $30 \mathrm{~mA}$ and $40 \mathrm{KV}$. The scanning range was $20^{\circ}-80^{\circ}$ in steps of 0.02 . The crystallite size $(t)$ and microstrain $(\varepsilon)$ were determined using the standard Williamson-Hall analysis [36]. The morphology of the resulting powders and distribution of reinforcement nanoparticles within the Al 7068 matrix was investigated by SEM (TESCAN model VEGA 3 LMU). The structure of mechanically alloyed powder was observed with a JOEL JEM $2100 \mathrm{~F}$ field emission transmission electron microscope (FETEM).

\section{RESULT AND DISCUSSION}

\subsection{Powder Morphology Evolution}

The scanning electron microscope images and $X$ Ray diffraction peaks of the as-received pure aluminium, $\mathrm{Al}_{2} \mathrm{O}_{3}, \mathrm{TiO}_{2}$ and $\mathrm{Cu}$ powders were shown as Fig. (1a-d). The aluminium powders were irregular in shape and had an average particle size of approxi-

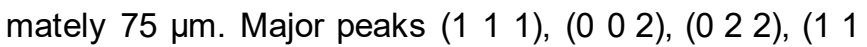
3 ) and ( $\left.\begin{array}{lll}2 & 2 & 2\end{array}\right)$ of aluminum with FCC crystal structures were obtained. The corresponding JCPDS Card Number is 98-008-4180. Peaks (2 11 1), (l $\left.\begin{array}{lll}2 & 1 & 1\end{array}\right),\left(\begin{array}{lll}0 & 2 & 1\end{array}\right)$ and $\left(\begin{array}{lll}1 & 1 & 3\end{array}\right)$ of $\mathrm{Al} 2 \mathrm{O} 3$ with FCC crystal structures were obtained. The corresponding JCPDS Card Number is 98-010-3822. Similarly all the eight major peaks $\left(\begin{array}{ll}1 & 1\end{array}\right)$,

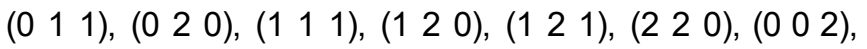
$\left(\begin{array}{lll}1 & 3 & 0\end{array}\right),\left(\begin{array}{lll}0 & 3 & 1\end{array}\right)$ and $\left(\begin{array}{lll}1 & 1 & 2\end{array}\right)$ of $\mathrm{TiO} 2$ with FCC crystal structures were obtained. The corresponding JCPDS Card Number is 98-002-2145. Three major peaks (1 1

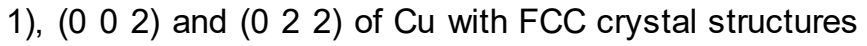
were obtained. The corresponding JCPDS Card Number is 98-009-2397. As received pure powders 

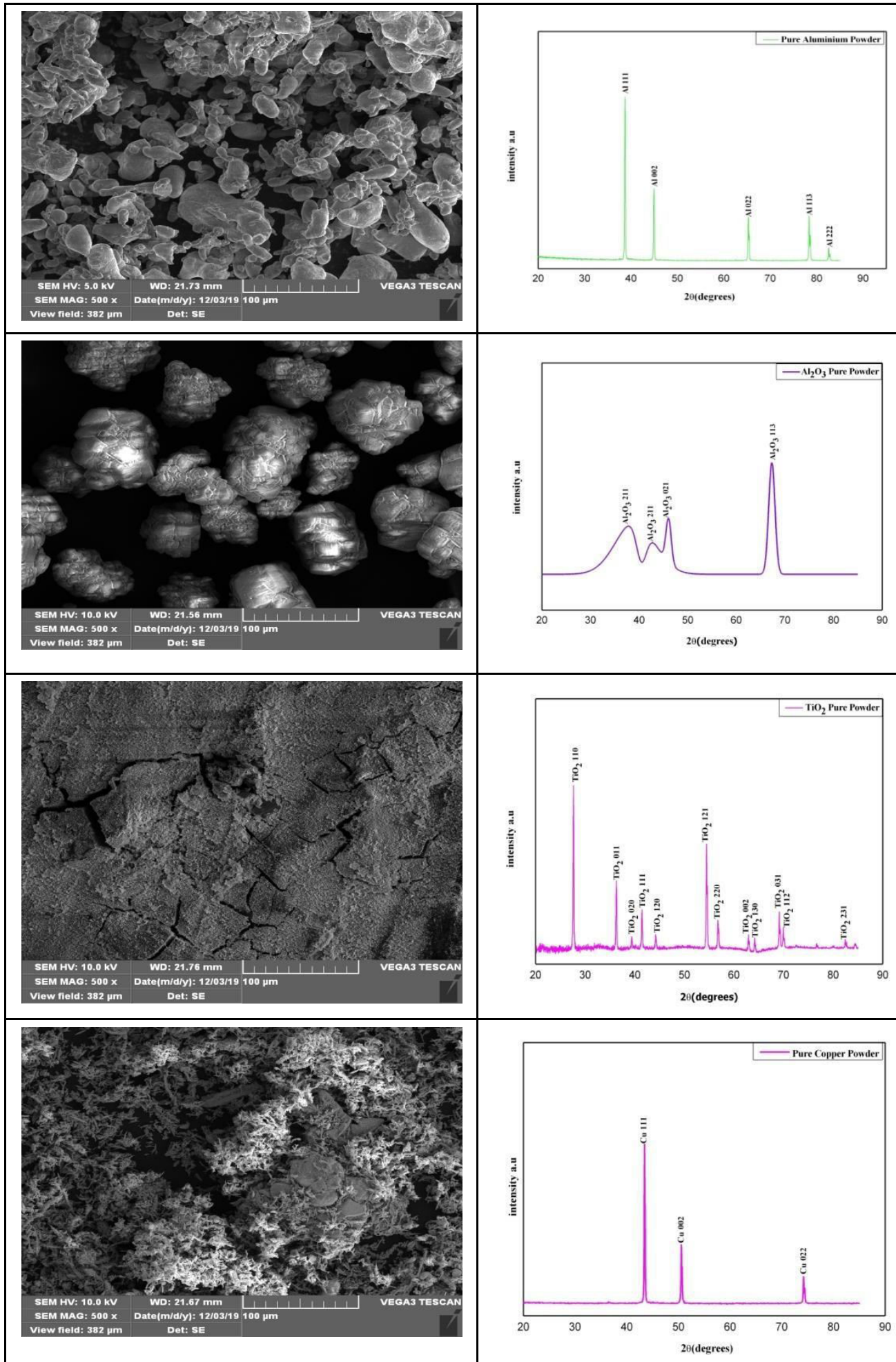

Figure 1: The SEM and XRD images of as received pure powders (a) Al (JCPDS Card Number: 98-008-4180); (b) Al2O3 (JCPDS Card Number: 98-010-3822); (c) TiO2 (JCPDS Card Number: 98-002-2415)and (d) Cu (JCPDS Card Number: 98-0092397).

morphology and sizes were confirmed by XRD and SEM.

The aluminium 7068 powder was ball milled up to $30 \mathrm{hr}$ after $5 \mathrm{hr}$ ball milling was stopped and taking one- gram sample out for morphological analysis. Repeated the process up to $30 \mathrm{hr}$ and kept it separate. Then aluminium 7068-2 wt. \% $\left(\mathrm{Al}_{2} \mathrm{O}_{3}, \mathrm{TiO}_{2}\right.$ and $\left.\mathrm{Cu}\right)$ powder particles were ball milled up to $30 \mathrm{hr}$. The mixture 
powder was ball milled at $30 \mathrm{hr}$ after $5 \mathrm{hr}$ ball milling was stopped and taking one- gram sample out. Repeated the process up to $30 \mathrm{hr}$ and kept it separate. Similarly, Aluminum $7068-4$ wt. $\%\left(\mathrm{Al}_{2} \mathrm{O}_{3}, \mathrm{TiO}_{2}\right.$ and $\left.\mathrm{Cu}\right)$ powder particles mixture was ball milled up to $30 \mathrm{hr}$. The mixture powder was ball milled up to $30 \mathrm{hr}$ after 5 $\mathrm{hr}$ ball milling was stopped and taking one- gram sample out. Repeated the process up to $30 \mathrm{hr}$ and kept it separate. During, ball milling the aluminium powder particle size was reduced. After the $30 \mathrm{hr}$ ball milling, the microparticles changed into nanoparticles. After the $5 \& 10 \mathrm{hr}$ of the particle is flattening and fracturing. After $15 \mathrm{hr}$ of the milling, cold welding was predominance. After the $20 \mathrm{hr}$ of the milling, fracturing was dominance. After the $25 \mathrm{hr}$ of the milling, equiaxed particle formation was started. After the $30 \mathrm{hr}$ of the milling, steady state was achieved. The SEM and XRD images of $\mathrm{Al}$ 7068-2 Wt. $\% \mathrm{Al}_{2} \mathrm{O}_{3}, \mathrm{TiO}_{2}$, and $\mathrm{Cu}$ nanocomposite powders as a function of the milling time and its morphological changes were shown in Fig. (2). From the XRD images, clear peaks of Aluminum, $\mathrm{Al}_{2} \mathrm{O}_{3}, \mathrm{TiO}_{2}$ and $\mathrm{Cu}$ were obtained and confirmed the preferred nanocomposite was $\mathrm{Al} 7068-2 \mathrm{Wt} . \% \mathrm{Al}_{2} \mathrm{O}_{3}$, $\mathrm{TiO}_{2}$, and $\mathrm{Cu}$ nanocomposite. In addition, a small $\mathrm{Zn}$ peak was obtained because of its weight fraction is more $(7.5 \mathrm{Wt} . \%)$ compared to other elements in $\mathrm{AA}$ 7068. Peaks for $\mathrm{Si}, \mathrm{Mg}, \mathrm{Fe}, \mathrm{Ti}, \mathrm{Cr}$ and $\mathrm{Mn}$ which are related to Al 7068 alloy, were not detectable due to their low volume fraction [37]. These components were expected to dissolve in the Al lattice. Fig. (2), X-ray diffraction images indicate that MA decreased the peak intensities and increased the peak width of Aluminium due to the structural refinement that resulted from the MA milling time.

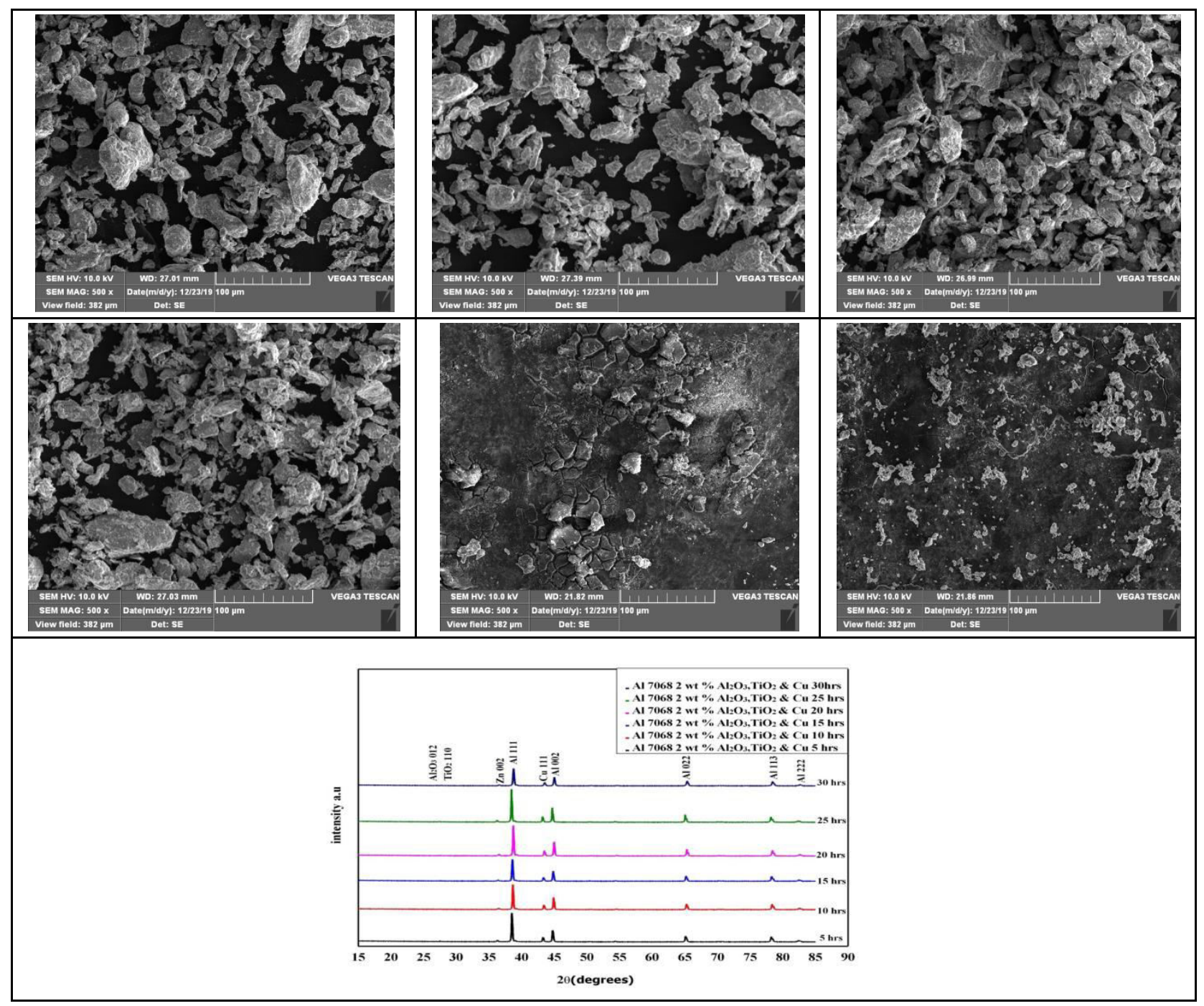

Figure 2: The SEM and XRD images of Al 7068-2 $\mathrm{Wt}_{0} \% \mathrm{Al}_{2} \mathrm{O}_{3}, \mathrm{TiO}_{2}$, and $\mathrm{Cu}$ nanocomposite powders as a function of the milling time after: (a) $5 \mathrm{~h}$; (b) $10 \mathrm{~h}$ (Particle flattening and fracturing) ; (c) $15 \mathrm{~h}$ (Cold welding predominance); (d) $20 \mathrm{~h}$ (Fracturing dominance) ; (e) $25 \mathrm{~h}$, (Equi-axed particle formation starts) and (f) $30 \mathrm{~h}$ (Steady state). 


\subsection{Structural Evaluation}

Table 3 shows the structural evaluation of AA 7068 2wt. $\% \mathrm{Al}_{2} \mathrm{O}_{3}, \mathrm{TiO}_{2}$ and $\mathrm{Cu}$ composite powder for various mechanical alloying times $(5 \mathrm{hr}, 10 \mathrm{hr}, 15 \mathrm{hr}, 20 \mathrm{hr}, 25 \mathrm{hr}$ and $30 \mathrm{hr}$ ). The crystallite size was decreased from 48 $\mathrm{nm}$ to $28 \mathrm{~nm}$ after $5 \mathrm{hr}$ to after $30 \mathrm{hr}$ of mechanical alloying. However, the lattice strain increased from 0.0037 to 0.005 as a function of the milling time due to the severe plastic deformation (SPD) by the highenergy ball mill. The slight decrease in the crystallite size and slight increase in the lattice strain indicate the attainment of steady state milling at $30 \mathrm{~h}$. This was shown in Fig. (3a). The Williamson-Hall analysis [36] was adapted to measure crystallite size $(t)$ and lattice strain $(\varepsilon)$ using the following expression:

$$
\beta_{h k l} \cdot \cos \theta_{h k l}=\left[\frac{k \lambda}{t}\right]+4 \varepsilon \cdot \sin \theta_{h k l}
$$

where $k$ is the shape factor (0.9), $\lambda$ is the wavelength of the X-ray radiation (1.5406), $\theta_{h k l}$ is the Bragg angle and $\beta_{h k l}$ is the full-width at half maximum after instrumental broadening correction. The first five Al reflections, peaks (l 111 1), ( $\left.\begin{array}{lll}0 & 0 & 2\end{array}\right),\left(\begin{array}{lll}0 & 2 & 2\end{array}\right),\left(\begin{array}{lll}1 & 1 & 3\end{array}\right)$ and (2 22 2) were used to construct a linear plot of $\beta_{h k l} \cos \theta_{h k l}$ against 4 $\sin \theta_{\text {hkl }}$. Crystallite size $(t)$ was obtained from the intercept and the strain $(\varepsilon)$ from the slope. The lattice parameter calculated by using interplanar spacing and miller indices. The actual lattice parameter was obtained from the intercept as described by Cullity [37] by constructing a linear plot between the calculated lattice parameter for each Bragg angle on the $\mathrm{Y}$-axis and the corresponding value of $\cos ^{2} \theta / \sin \theta$ on the $X$ axis. The lattice parameter reported for pure FCC Al at room temperature is $4.0496 \AA$ [37]. The lattice parameter reported for $\mathrm{Al} 6061-2$ wt. $\% \quad \mathrm{Al}_{2} \mathrm{O}_{3}$ nanocrystalline is $4.0456 \AA$ after milling for $30 \mathrm{~h}$ [35]. In this investigation, the lattice parameter for the Al 70682 wt. $\% \mathrm{Al}_{2} \mathrm{O}_{3}, \mathrm{TiO}_{2}$ and $\mathrm{Cu}$ nanocrystalline matrix was

Table 3: Structural Characterization of $\mathrm{AA} 7068$-2wt. $\% \mathrm{Al}_{2} \mathrm{O}_{3}, \mathrm{TiO}_{2}$ and $\mathrm{Cu}$ Composite Powder for Various Ball Milling Times (hr)

\begin{tabular}{|c|c|c|c|c|c|}
\hline SI. No. & Ball Milling (hrs) & Crystallite Size (nm) & Lattice Strain $(\varepsilon)$ & Lattice Parameter (a) A & Unit Cell Volume (V) $\mathbf{m}^{3}$ \\
\hline \hline 1 & 5 & 48 & 0.003742 & 4.0490 & 66.38092 \\
\hline 2 & 10 & 43 & 0.004112 & 4.0480 & 66.33175 \\
\hline 3 & 15 & 37 & 0.004571 & 4.0462 & 66.24331 \\
\hline 4 & 20 & 34 & 0.004985 & 4.0448 & 66.17457 \\
\hline 5 & 25 & 31 & 0.005500 & 4.0425 & 66.06175 \\
\hline 6 & 30 & 28 & 0.006140 & 4.0410 & 65.98824 \\
\hline
\end{tabular}

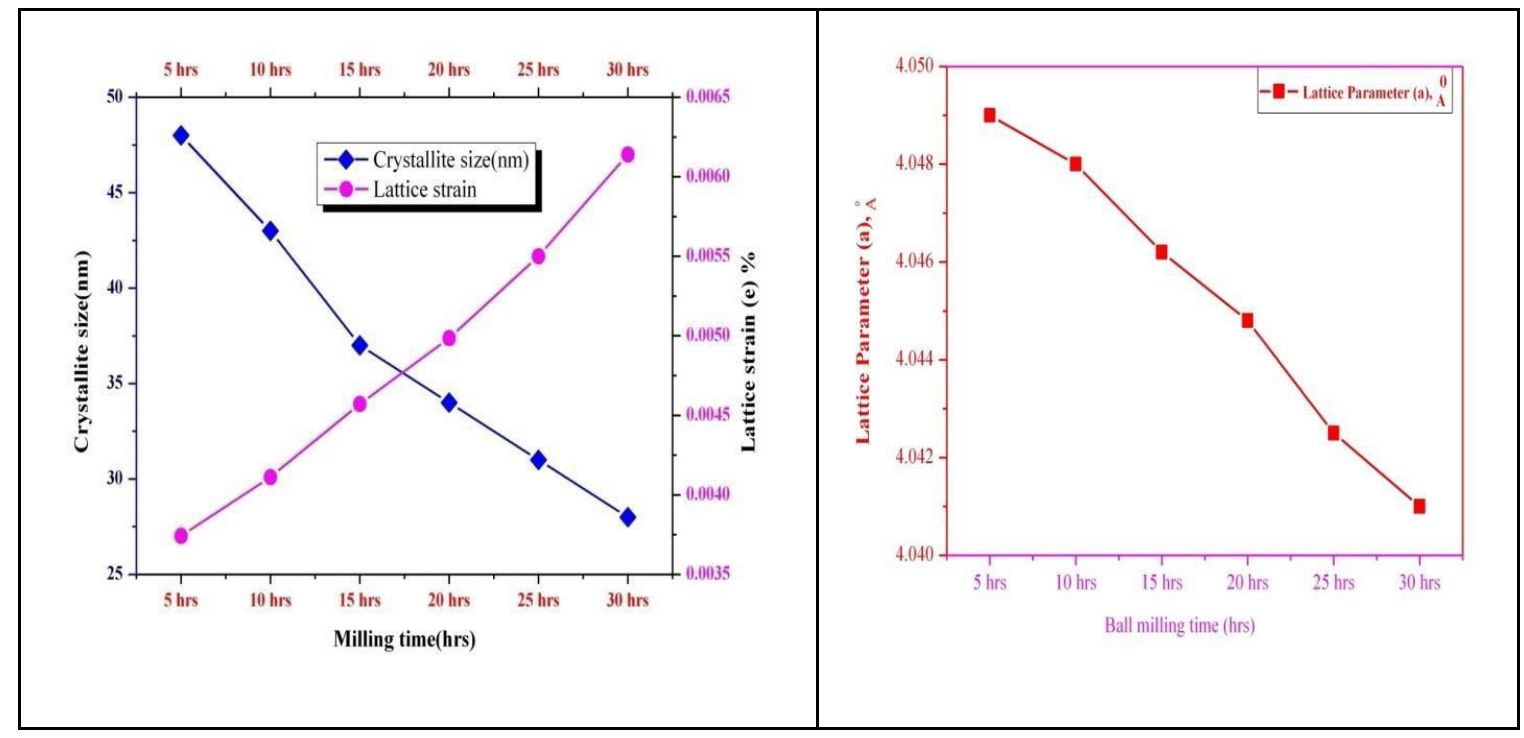

Figure 3: (a) Change in crystallite size and lattice strain of $\mathrm{AA} 7068-2 \mathrm{wt} . \% \mathrm{Al}_{2} \mathrm{O}_{3}, \mathrm{TiO}_{2}$ and $\mathrm{Cu}$ as a function milling time; (b) lattice parameter as function of milling time. 
$4.0414 \AA$ after milling for $30 \mathrm{hr}$. So that the adding reinforcement, reduces lattice parameters values slightly.

Fig. (4a) shows the bright field emission transmitssion electron microscopy (FETEM) image of Al 7068-2 wt. \% $\mathrm{Al}_{2} \mathrm{O}_{3}, \mathrm{TiO}_{2}$ and $\mathrm{Cu}$ after $30 \mathrm{hr}$. From that image, bright areas represent nanocrystalline aluminium matrix and dark areas represent $\mathrm{cu}$ and $\mathrm{TiO}_{2}$ nanoparticles. In addition, alumina nanoparticles were identified. From Fig. (4a), the observed grain size of the a-Al matrix is almost equi-axed and at an ultra-fine level. Further, the $\mathrm{Al}_{2} \mathrm{O}_{3}, \quad \mathrm{TiO}_{2}$ and $\mathrm{Cu}$ nanoparticles were uniformly distributed and embedded in the $\alpha-A l$ matrix. Fig. (4b) shows the selected area diffraction pattern and confirms the nanocrystalline composite powder.

Fig. (5) Shows the DSC curve of AA 7068-2.0 wt. \% $\mathrm{Al} 2 \mathrm{O} 3, \mathrm{TiO} 2$ and $\mathrm{Cu}$ nanocomposite powders after 30 hrs of Ball milling. DSC curve of Al 7068-2 wt.\% Al2O3, $\mathrm{TiO} 2$ and $\mathrm{Cu}$ nanocomposites analysed, because The 2 wt. \% of reinforcement content in metal matrix gave optimum mechanical properties (Hardness value). Hence, Al 7068-2 wt. \% Al2O3, TiO2 and $\mathrm{Cu}$ nanocomposites were taken for analysis

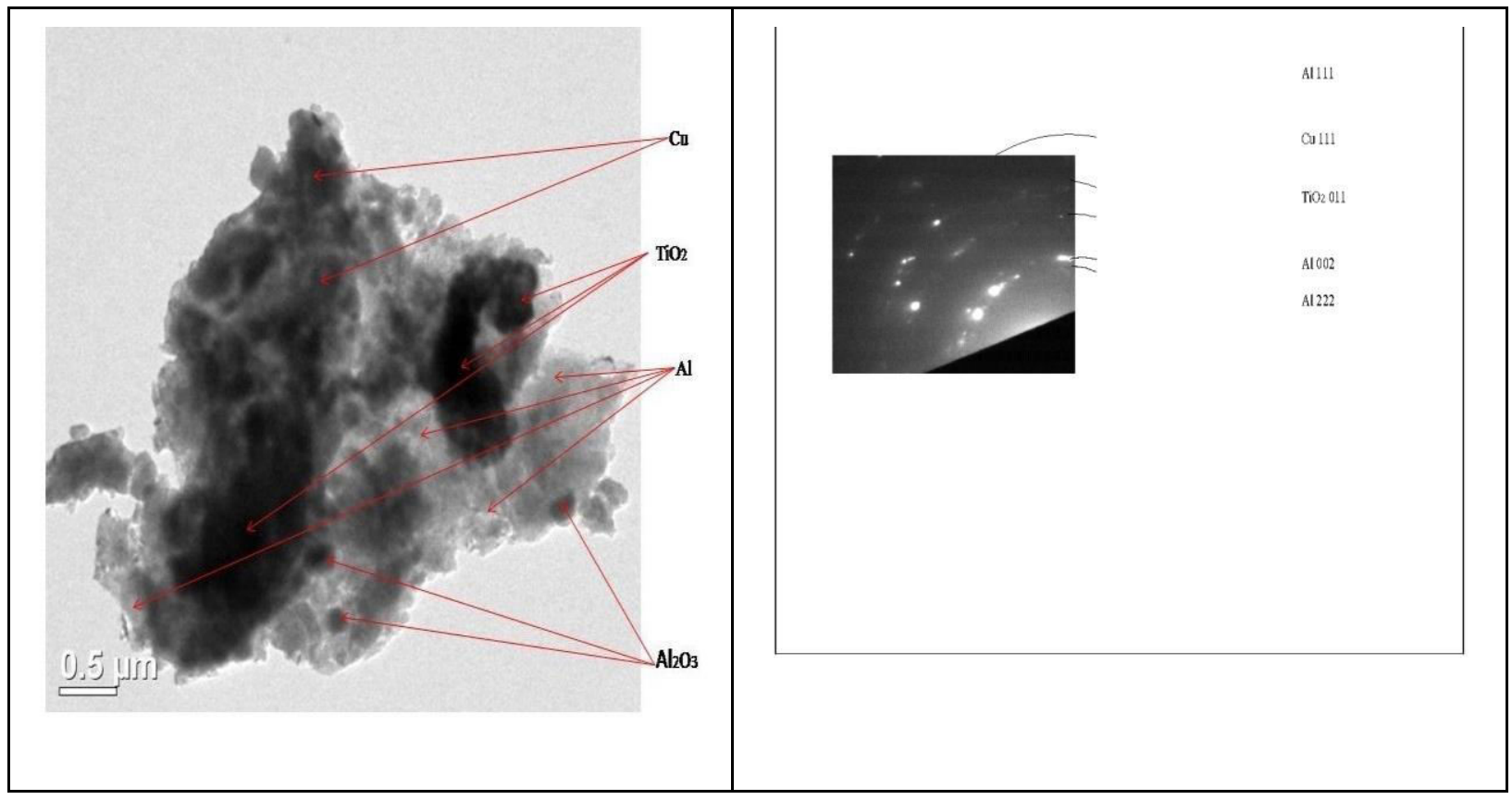

Figure 4: (a) Bright Field Emission Transmission electron microscopy (FETEM) image of Al 7068-2 wt. $\% \mathrm{Al}_{2} \mathrm{O}_{3}, \mathrm{TiO}_{2}$ and $\mathrm{Cu}$ after $30 \mathrm{hr}$; (b) Corresponding SAD ring pattern.

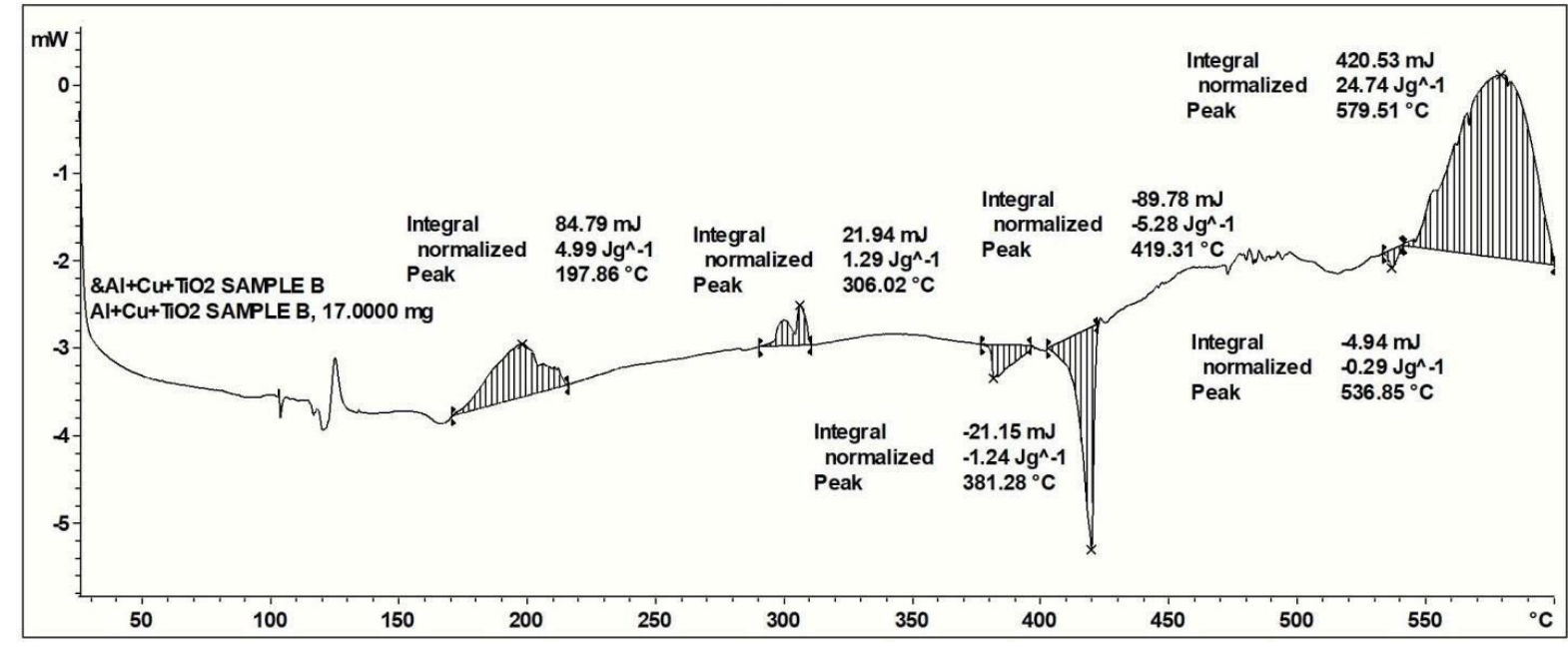

Figure 5: The DSC curve of $\mathrm{AA} 7068-2.0$ wt. $\% \mathrm{Al}_{2} \mathrm{O}_{3}, \mathrm{TiO}_{2}$ and $\mathrm{Cu}$ nanocomposite powders after $30 \mathrm{hrs}$ of Ball milling. 
The differential scanning calorimetry used to measure enthalpy changes due to changes in the physical and chemical properties of a material as a function of temperature or time. Heat flow is directly proportional to the capacity of the material for the given temperature. The studies were conducted by using 17 $\mathrm{mg}$ sample in an aluminium sample holder by purging of pure nitrogen gas at an airflow rate $50 \mathrm{ml} / \mathrm{min}$ with a temperature range of $25^{\circ} \mathrm{C}$ to $600^{\circ} \mathrm{C}$ through a heating rate of $10^{\circ} \mathrm{C} / \mathrm{min}$. The endothermic peak at $536.85^{\circ} \mathrm{C}$ corresponds to the melting of aluminium, which was followed by a steady-state exothermic reaction at $579.51^{\circ} \mathrm{C}$. The higher calorific value obtained from this study was $(\Delta \mathrm{H}) 24.74 \mathrm{~J} / \mathrm{g}$.

\subsection{Density and Hardness Measurement}

Table 4 shows the density and hardness measurement of prepared nanocomposites. Theoretical density was calculated by the rule of mixture. The green and sintered densities of the prepared nanocomposites were determined to employ the Archimedes principle. The growth of the theoretical, green and sintered densities (\%), significantly increased, due to the very fine particle size and distribution of reinforcements in a soft alloy matrix. Fig. (6a-b) shows the relation between theoretical, green and sintered densities. The density positively correlated with the reinforcement content $(0 \%, 2 \%$ and $4 \%)$ The densities of these nanocomposites was increased after sintering. The growth of the theoretical density (\%) significantly increased, due to the very fine particle size and distribution of reinforcements in a soft alloy matrix. This effect was confirmed by our earlier results (33-35). The Hardness test was conducted by the Brinell Hardness Testing Machine. The experimental error was less than $10 \%$ in the hardness measurement. The Brinell hardness number $173.2 \mathrm{BHN}, 192 \mathrm{BHN}$ and $184 \mathrm{BHN}$ values were obtained for $\mathrm{Al} 7068-0$ wt. $\% \mathrm{Al}_{2} \mathrm{O}_{3}, \mathrm{TiO}_{2}$ and $\mathrm{Cu}$ nanocrystalline, Al 7068-2 wt. $\% \mathrm{Al}_{2} \mathrm{O}_{3}, \mathrm{TiO}_{2}$ and $\mathrm{Cu}$ nanocomposites and $\mathrm{Al}$ 7068-4 wt. $\% \mathrm{Al}_{2} \mathrm{O}_{3}, \mathrm{TiO}_{2}$ and $\mathrm{Cu}$ nanocomposites respectively.

The higher amount of reinforcement (More than 2 Wt. \%) will lead to particle agglomeration and deteriorate mechanical properties. Al 7068-2 Wt.\%

Table 4: Density and Hardness Measurement

\begin{tabular}{|c|c|c|c|c|c|}
\hline SI. No & Nanocom posites & $\begin{array}{l}\text { Theoretical } \\
\text { Density (g/cc) }\end{array}$ & \multicolumn{2}{|c|}{ Actual Density (g/cc) } & $\begin{array}{l}\text { Brinell Hardness } \\
\text { Num ber (BHN) }\end{array}$ \\
\hline 1 & $\mathrm{Al} 7068-0$ w t. $\% \mathrm{Al}_{2} \mathrm{O}_{3}, \mathrm{TiO}_{2}$ and copper & 2.85 & 2.62416 & 2.64138 & 173 \\
\hline 2 & $\mathrm{Al} 7068-2$ w t. $\% \mathrm{Al}_{2} \mathrm{O}_{3}, \mathrm{TiO}_{2}$ and copper & 3.02254 & 2.73994 & 2.76988 & 192 \\
\hline 3 & Al 7068-4 w t. $\% \mathrm{Al}_{2} \mathrm{O}_{3}, \mathrm{TiO}_{2}$ and copper & 3.19508 & 2.90685 & 2.95462 & 184 \\
\hline
\end{tabular}

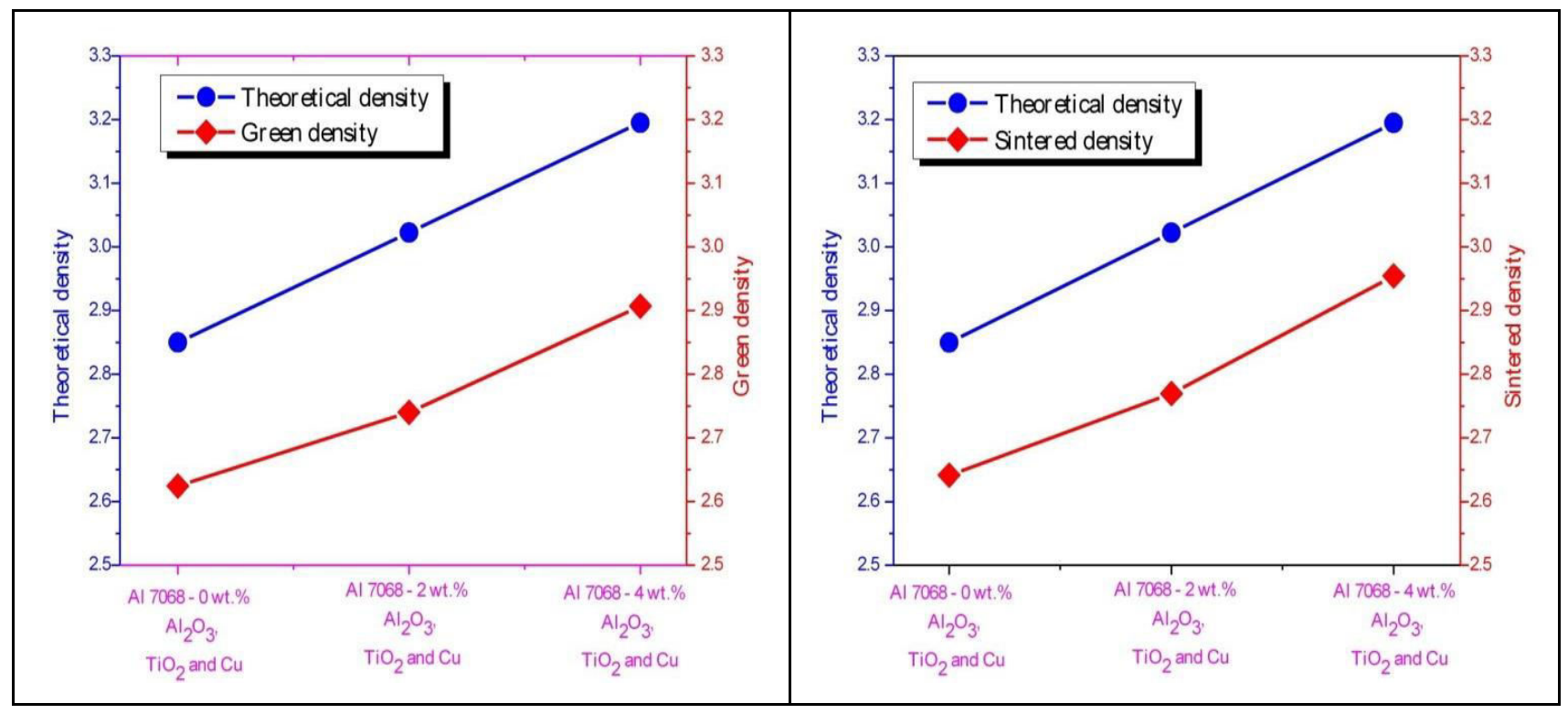

Figure 6: (a) Theoretical density Vs Green density; (b) Theoretical density Vs Sintered density. 
$\mathrm{Al} 2 \mathrm{O} 3, \mathrm{TiO} 2$ and $\mathrm{Cu}$ nanocomposites gave more hardness value than $\mathrm{Al} 7068$-4 Wt.\% Al2O3, TiO2 and $\mathrm{Cu}$ nanocomposites. Because, the agglomeration of particles will lead to decrease mechanical properties. Furthermore, the addition of reinforcement content gave a reduction in hardness. Fig. (7) shows Brinell hardness number (BHN) of prepared AA 7068 nanocomposites after $30 \mathrm{hrs}$ of MA. The $2 \mathrm{Wt}$. \% of reinforcement content in metal matrix gave optimum mechanical properties and it was confirmed by previous studies [32-34].

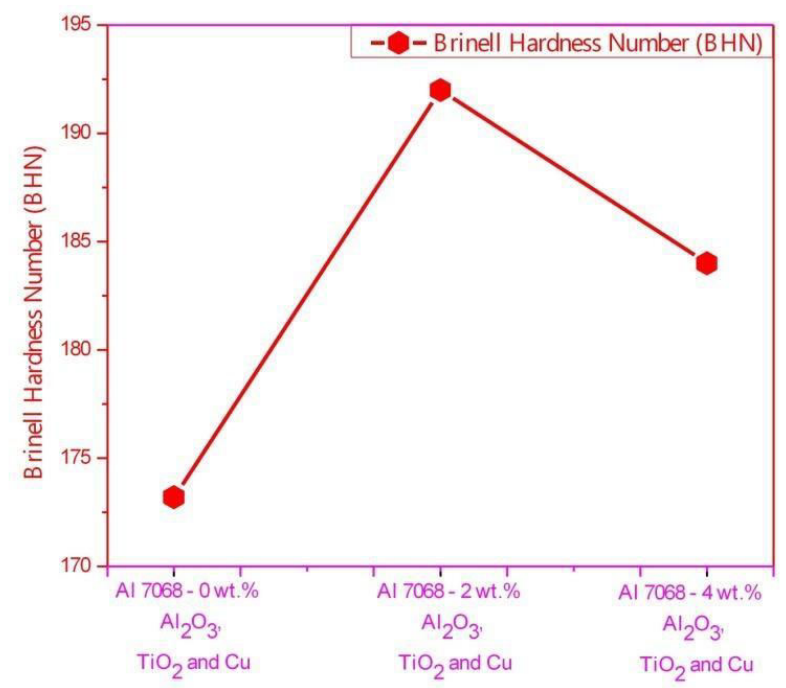

Figure 7: Brinell hardness number $(B H N)$ of prepared $A A$ 7068 nanocomposites after $30 \mathrm{hrs}$ of MA.

\section{CONCLUSION}

The present study examined AA7068-xwt. $\% \mathrm{Al}_{2} \mathrm{O}_{3}$, $\mathrm{TiO}_{2}$ and $\mathrm{Cu}(\mathrm{x}=0$ wt. $\%$, 2wt. \%, and 4wt. \%) nanocomposite prepared by powder metallurgy route and synthesis, structural changes, characterization and mechanical behavior.

The powder morphology of prepared nanocomposites was investigated and reported as a function of milling time. An XRD result reveals that there are no intermetallic compounds formed in the milled powder after $30 \mathrm{hr}$ of mechanical alloying. An equiaxed and almost spherical powder morphology was obtained after $30 \mathrm{hr}$ mechanical alloying which was characteristic of the steady state. The reinforcement particles were well embedded and uniformly distributed in $\mathrm{Al}$ 7068 metal matrix composites. It was confirmed by bright-field emission transmission electron microscopy (FETEM) image and selected area diffraction (SAD) ring pattern. From the DSC curve of AA 7068-2.0 wt. \% $\mathrm{Al}_{2} \mathrm{O}_{3}, \mathrm{TiO}_{2}$ and $\mathrm{Cu}$ nanocomposite powders after $30 \mathrm{hrs}$ of mechanical alloying, the endothermic peak at $536.85^{\circ} \mathrm{C}$ corresponds to the melting of aluminium which was followed by a steady-state exothermic reaction at $579.51^{\circ} \mathrm{C}$. The higher calorific value of $(\Delta \mathrm{H})$ $24.74 \mathrm{~J} / \mathrm{g}$. Density and hardness measurement was analyzed. Al 7068-2 wt. \% $\mathrm{Al}_{2} \mathrm{O}_{3}, \mathrm{TiO}_{2}$ and $\mathrm{Cu}$ nanocomposites gave better hardness value $192 \mathrm{BHN}$ and it was $11 \%$ more than unreinforced nanocrystalline.

Densification behavior, wear behavior and tensile and compression strength measurements for the above-prepared nanocomposite materials will be analysed and addressed in future work.

\section{REFERENCES}

[1] Zhang XX. Mechanical properties of ABOw+MVNTs/AI hybrid composites made by squeeze cast technique. Mater Lett 2007;61(16):3504-06. https://doi.org/10.1016/i.matlet.2006.11.113

[2] Farman Ali, Muhammed Waseem, Rafaqat Khurshid, Adeel Afzal. TiO2 reinforced high-performance epoxy-co-polyamide composite coatings. Progress in Organic Coatings 2020;146: 105726.

https://doi.org/10.1016/i.porgcoat.2020.105726

[3] Siddabathula Madhusudan, Mohammed Moulana Mohiuddin Sarcar, Narsipalli Bhargava Rama Mohan Rao. Mechanical properties of Aluminum-Copper (p) composite metallic materials. Journal of Applied Research and Technology. 2016;14 (5):293-299. https://doi.org/10.1016/j.jart.2016.05.009

[4] K.Jhon Joshua, P. Sherjin, J. Perinba Selvin Raj. The analysis of ball-milled aluminium alloy 7068 metal pow ders. SSRG International Journal of Mechanical Engineering (SSRG - IJME). 2017; 4 (8). https://doi.org/10.14445/23488360/IJME-V4I8P102

[5] K.Jhon Joshua, S. J. Vijay, D. Philip Selvaraj, P. Ramkumar. Influence of $\mathrm{MgO}$ particles on Microstructural and mechanical behaviour of AA7068 Metal Matrix Composites. Materials Science and Engineering 2017; 247: 012011. https://doi.org/10.1088/1757-899X/247/1/012011

[6] J.Lakshmipathy, S. Rajesh Kannan, K.Manisekar, S.Vinoth Kumar. Effect of reinforcement and Tribological Behaviour of AA7068 Hybrid Composites Manufactured through Pow der Metallurgy Techniques. Applied Mechanics and Materials 2017; 867:19-28, 2017. https://doi.org/10.4028/w w w.scientific.net/AMM.867.19

[7] M. Madhusudhan, G.J.Naveen, K.Mahesha. Mechanical Characterization of AA7068-ZrO2 reinforced Metal Matrix Composites. Materials Today: Proceedings 2017: 4 (2): 31223130. https://doi.org/10.1016/i.matpr.2017.02.196

[8] V. Sridhar, Ch. Ratnam, M. Ashok Chakravarthy. Synthesis and Mechanical Characterization of Magnesium Reinforced With Nano Alumina Composites. Materials Today: Proceedings 2017; 4 (2); 3131-3140. https://doi.org/10.1016/i.matpr.2017.02.197

[9] Ali Hubi Haleem, Newfal Zuheir and Newal Muhammad Daw ood. Preparing and Studying Some Mechanical Properties of Aluminium Matrix Composite Materials Reinforced by $\mathrm{Al} 2 \mathrm{O} 3$ particles. Journal of Babylon University/Engineering Sciences 2012; 20 (1).

[10] M. Karbalaei Akbari, H.R.Baharvandi, and O.Mirzaee. Fabrication of nano-sized $\mathrm{Al} 2 \mathrm{O} 3$ reinforced casting aluminium composite focusing on preparation process of 
reinforcement pow ders and evaluation of its properties. Composites: Part B. 2013; 55: 426-432.

https://doi.org/10.1016/j.compositesb.2013.07.008

[11] M. Karbalaei Akbari, H.R.Baharvandi, and O.Mirzaee. Investigation of particle size and reinforcement content on mechanical properties and fracture behaviour of A356-Al2O3 composite fabricated by the vortex method. Journal of Composite Materials. 2014; 48 (27):3315-3330. https://doi.org/10.1177/0021998313507618

[12] A.Baradesw aran and A.Elayaperumal. Study on mechanical and wear properties of Al 7075/Al2O3/graphite hybrid composites. Composites: Part B. 2014; 56:464-471. https://doi.org/10.1016/i.compositesb.2013.08.013

[13] Chen, F., Wang, T. M., Chen, Z. N., Mao, F., Han, Q. and Cao, Z. Q. Microstructure, mechanical properties and wear behaviour of $\mathrm{Zn}-\mathrm{Al}-\mathrm{Cu}-\mathrm{TiB} 2$ in situ composites. Transactions of Nonferrous Metals Society of China. 2015; 25:103-111. https://doi.org/10.1016/S1003-6326(15)63584-1

[14] S. Dhanalakshmi, N.Mohanasundararaju and P.G. Venkatekrishnan. Preparation and mechanical characterization of stir cast hybrid Al7075-Al2O3-B4C metal matrix composites. Applied Mechanics and Materials. 2014; 92-594:705-710.

https://doi.org/10.4028/www.scientific.net/AMM.592-594.705

[15] Kumar, A., Lai, S. and Kumar, S. Fabrication and Characterization of A359/Al2O3 metal matrix composite using the electromagnetic stir casting method. Journal of Materials Research and Technology. 2013; 2(3): 250-254. https://doi.org/10.1016/.jmrt.2013.03.015

[16] Mahallawi, I.E., Shash, Y., Rashad, R.M., Abdelaziz, M.H., Mayer, J. and Schw edt, A. Hardness and w ear behaviour of semi-solid cast A390 alloy reinforced with Al2O3 and TiO2 nanoparticles. Arabian Journal for Science and Engineering. 2014; 39:5171-5184.

https://doi.org/10.1007/s13369-014-1179-3

[17] A. Mazahery and M.Ostadshabani. Investigation on mechanical properties of nano-Al2O3-reinforced aluminium matrix composites. Journal of Composite Materials. 2011; 45(24):2579-2586

https://doi.org/10.1177/0021998311401111

[18] Y.Sahin and K.E.Oksuz. Tribological behaviour of Al2014Al2O3 particle reinforced composites produced by pow der metallurgy method. Journal of the Balkan Tribological Association. 2013; 19(2):190-201.

[19] S.A. Sajjadi, H.R.Ezatpour, and M.T.Parizi. Comparison of microstructure and mechanical properties of A356 aluminium alloy/AI2O3 composites fabricated by stir and compo-casting processes. Materials \& Design. 2012; 34:106-111. https://doi.org/10.1016/j.matdes.2011.07.037

[20] S.A. Sajjadi, M.T.Parizi, H.R.Ezatpour, A.Sedghi. Fabrication of A356 composite reinforced with micro and nano Al2O3 particles by a developed compocasting method and study of its properties. Journal of Alloys and Compounds. 2012; 511:226-231. https://doi.org/10.1016/ij.jallcom.2011.08.105

[21] K. Sekar, K.Allesu and M.A.Joseph. Effect of T6 heat treatment in the microstructure and mechanical properties of A356 reinforced $w$ ith nano $\mathrm{Al} 2 \mathrm{O} 3$ particles by combination effect of stir and squeeze casting. Procedia Materials Science. 2014; 5:444-453.

https://doi.org/10.1016/..mspro.2014.07.287

[22] S. Tahamtan, A.Halvaee, M.Emamy, and M.S.Zabihi. Fabrication of Al/A206-Al2O3 nano/micro composite by combining ball milling and stir casting technology. Materials \& Design. 2013; 49:347-359. https://doi.org/10.1016/j.matdes.2013.01.032

[23] K.Umanath, K.Palanikumar, and S.T.Selvamani. Analysis of dry sliding w ear behaviour of Al6061/SiC/AI2O3 hybrid metal matrix composites. Composites: Part B. 2013; 53:159-168. https://doi.org/10.1016/j.compositesb.2013.04.051
[24] Mohammad Khoshghadam-Pireyousefan, Roohollah Rahmanifard, Lubomir Orovcik, Peter Svec, Volker Klemm. Application of a novel method for fabrication of graphene reinforced aluminium matrix nanocomposites: Synthesis, microstructure, and mechanical properties. Materials Science \& Engineering A. 2020; 772:138820

https://doi.org/10.1016/i.msea.2019.138820

[25] Avwerosuoghene Moses Okoroa, Ronald Machakab, Senzeni Sipho Lephuthinga, Samuel Ranti Okea, Mary Ajimegoh Aw otundea, Peter Apata Olubambia, Evaluation of the sinterability, densification behaviour and microhardness of spark plasma sintered multiwall carbon nanotubes reinforced Ti6Al4V nanocomposites. Ceramics International.2019; 45:19864-19878.

https://doi.org/10.1016/i.ceramint.2019.06.242

[26] M.K.Akbari, S Rajabi, K Shirvanimoghaddam and H.R.Baharvandi. Wear and friction behaviour of nanosized TiB2 and TiO2 particle-reinforced casting A356 aluminium nanocomposites: A comparative study focusing on particle capture in the matrix. Journal of Composite Materials 2015;161(29):3665-3681

\section{https://doi.org/10.1177/0021998314568327}

[27] Meysam Toozandehjani, Khamirul Amin Matori, Farhad Ostovan, Sidek Abdul Aziz and Md Shuhazlly Mamat. Effect of Milling Time on the Microstructure, Physical and Mechanical Properties of Al-Al2O3 Nanocomposite Synthesized by Ball Milling and Pow der Metallurgy. Materials 2017; 10(11):1232. https://doi.org/10.3390/ma10111232

[28] Yilong Yang, Zhilin Liu, Ripeng Jiang, Ruiqing Li, Xiaoqian Li. Microstructural evolution and mechanical properties of the AA2219/TiC nanocomposite manufactured by ultrasonic solidification. Journal of Alloys and Compounds 2019;811:151991.

https://doi.org/10.1016/j.jallcom.2019.151991

[29] J.Osten, B.Milkereit, M.Reich, B.Yang, A.Springer, K.Now ak, O.Kessler. Development of Precipitation Hardening Parameters for High Strength Alloy AA 7068. Materials. 2020;13: 918.

\section{https://doi.org/10.3390/ma13040918}

[30] Amin Azimi, Ali Shokuhfar, Omid Nejadseyfi, Hamid Fallahdoost, Saeid Salehi. Optimizing consolidation behaviour of Al 7068-TiC nanocomposites using Taguchi statistical analysis. Transaction of Nonferrous Metals Society of China.2015; 25(8):2499-2508. https://doi.org/10.1016/S1003-6326(15)63868-7

[31] R. Taherzadeh Mousavian, S. Behnamfard, R. Azari Khosroshahi, J. Zava Snik, P. Ghosh, S. Krishnamurthy, A. Heidarzadeh, D. Brabazon. Strength-ductility trade-off via SiC nanoparticle dispersion in A356 aluminium matrix. Materials Science \& Engineering A 2020;771: 138639. https://doi.org/10.1016/i.msea.2019.138639

[32] K.R. Ramkumar, S. Natarajan. Tensile properties and strengthening effects of $\mathrm{Al} 3003$ alloy w eldment reinforced with TiO2 nanoparticles. Composites Part B 2019, 175:107159.

https://doi.org/10.1016/j.compositesb.2019.107159

[33] D. Jeyasimman, S. Sivasankaran, K. Sivaprasad, R. Narayanasamy, R.S. Kambali. An investigation of the synthesis, consolidation and mechanical behaviour of $\mathrm{Al}$ 6061 nanocomposites reinforced by TiC via mechanical alloying. Materials and Design 2014; 57: 394-404. https://doi.org/10.1016/i.matdes.2013.12.067

[34] D. Jeyasimman, K.Sivaprasad, S.Sivasankaran R.Narayanasamy. Fabrication and consolidation behaviour of Al 6061 nanocomposite pow ders reinforced by multi-w alled carbon nanotubes". Pow der Technology. 2014; 258:189-197. https://doi.org/10.1016/i.pow tec.2014.03.039

[35] D. Jeyasimman, K.Sivaprasad, S.Sivasankaran, R.Ponalagusamy, R.Narayanasamy, Vijayakumar lyer. 
Microstructural observation, consolidation and mechanical behaviour of AA 6061 nanocomposites reinforced by $\gamma-\mathrm{Al} 2 \mathrm{O} 3$ nanoparticles. Advanced Pow der Technology. 2015; 26:139148.

https://doi.org/10.1016/i.apt.2014.08.016
[36] G.K. Williamson, W.H.Hall. X-ray line broadening from field aluminium and w olfram. Acta Metall 1953; 1(1):22-31. https://doi.org/10.1016/0001-6160(53)90006-6

[37] Cullity B.D. Elements of X-ray diffraction 2nd edition AddisonWesley.London.UK.1978.

Received on 15-11-2020

Accepted on 20-12-2020

Published on $30-12-2020$

DOI: https://doi.org/10.31875/2410-4701.2020.07.09

(C) 2020 Sathiyarasu et al:; Zeal Press.

This is an open access article licensed under the terms of the Creative Commons Attribution Non-Commercial License (http://creativecommons .org/licenses/by-nc/3.0/) which permits unrestricted, non-commercial use, dis tribution and reproduction in any medium, provided the work is properly cited. 